Short Communication

\title{
In vitro evaluation of novel reverse transcriptase inhibitors TAF (tenofovir alafenamide) and OBP-601 (2,3-didehydro-3-deoxy-4-ethynylthymidine) against multi-drug resistant primary isolates of HIV-2
}

\author{
Inês Bártolo ${ }^{\mathrm{a}, * *}$, Pedro Borrego ${ }^{\mathrm{a}, \mathrm{b}}$, Perpétua Gomes ${ }^{\mathrm{c}, \mathrm{f}}$, Fátima Gonçalves ${ }^{\mathrm{c}}$, Umbelina Caixas ${ }^{\mathrm{d}}$, \\ Inês V. Pinto ${ }^{\mathrm{e}}$, Nuno Taveira ${ }^{\mathrm{a}, \mathrm{f}, *}$ \\ ${ }^{a}$ Research Institute for Medicines (iMed.ULisboa), Faculdade de Farmácia, Universidade de Lisboa, Avenida Professor Gama Pinto, 1649-003, Lisboa, Portugal

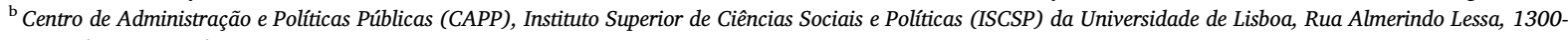 \\ 663, Lisboa, Portugal \\ c Laboratório de Biologia Molecular, Serviço de Patologia Clínica, Centro Hospitalar Lisboa Ocidental - Hospital de Egas Moniz, Rua da Junqueira, nº 126 1349-019, \\ Lisboa, Portugal \\ ${ }^{\mathrm{d}}$ Serviço de Medicina 1.4, Hospital de S. José, Centro Hospitalar Lisboa Central,- EPE, and Faculdade de Ciências Médicas, Universidade Nova de Lisboa, Centro de Estudos \\ de Doenças Crónicas - CEDOC, Rua Câmara Pestana nº6, 6-A, 1150-082, Lisboa, Portugal \\ ${ }^{\mathrm{e}}$ Medicina Interna, Hospital de Cascais Dr. José de Almeida, Av. Brigadeiro Victor Novais Gonçalves, 2755-009, Alcabideche, Portugal \\ ${ }^{\mathrm{f}}$ Centro de Investigação Interdisciplinar Egas Moniz (CiiEM), Instituto Universitário Egas Moniz (IUEM), Campus Universitário, Quinta da Granja Monte de Caparica, \\ 2829 - 511, Caparica, Portugal
}

\section{A R T I C L E I N F O}

\section{Keywords:}

HIV-2

Susceptibility to TAF

TDF and OBP-601

Resistance mutations

\begin{abstract}
A B S T R A C T
New antiretroviral drugs are needed to treat HIV-2 infected patients failing therapy. Herein, we evaluate the activity of novel reverse transcriptase inhibitors tenofovir alafenamide (TAF) and OBP-601(2,3-didehydro-3deoxy-4-ethynylthymidine) against primary isolates from HIV-2 infected patients experiencing virologic failure. TAF and OBP-601 were tested against twelve primary isolates obtained from nine drug-experienced patients failing therapy and three drug naïve patients using a single-round infectivity assay in TZM-bl cells. The RTcoding region of pol was sequenced and the GRADE algorithm was used to identify resistance profiles and mutations. TAF and OBP-601 inhibited the replication of almost all isolates at a median $\mathrm{EC}_{50}$ of $0.27 \mathrm{nM}$ and $6.83 \mathrm{nM}$, respectively. Two isolates showed moderate-level resistance to OBP-601 or TAF and two other isolates showed high-level resistance to OBP-601 or to both drugs. With one exception, all resistant viruses had canonical nucleoside reverse transcriptase inhibitors (NRTIs)-associated resistance mutations (K65R, N69S, V111I, Y115F, Q151M and M184V). Our results show that TAF has potent activity against most multi-drug resistant HIV-2 isolates and should be considered for the treatment of HIV-2 infected patients failing therapy.
\end{abstract}

There are about 1-2 million people infected with HIV-2 worldwide most living in West Africa (Gottlieb et al., 2008), Portugal (Carvalho et al., 2012), France (Cazein et al., 2015) and India (Gurjar et al., 2009). HIV-2 is less pathogenic than HIV-1 and progression to AIDS in the absence of antiretroviral treatment (ART) is much slower in HIV-2infected patients (on average $\geq 20$ years for HIV-2 vs 10 years for HIV1 infection) (Damond et al., 2011; Gottlieb et al., 2002). As for HIV-1, ART prevents disease progression to AIDS and death (de Silva et al., 2008; Hansmann et al., 2005). However, options available for the treatment of HIV-2 infected patients are still limited since, in contrast to
HIV-1, HIV-2 is naturally resistant to nonnucleoside reverse transcriptase inhibitors (NNRTIs) and fusion inhibitors, and it presents a reduced sensitivity to some protease inhibitors (PIs) [reviewed in (Menendez-Arias and Alvarez, 2014)]. Moreover, most ART regimens used in HIV-1 infected patients are unable to suppress viral replication in HIV-2 infected patients or to significantly increase the number of $\mathrm{CD}^{+}{ }^{+}$T lymphocytes (Soares et al., 2011). Finally, HIV-2 has a lower genetic barrier to resistance to current drugs compared to HIV-1 (Ntemgwa et al., 2007, 2009). Hence, there is an urgent need for new antiretroviral drugs to treat HIV-2 infection.

\footnotetext{
* Corresponding author. Research Institute for Medicines (iMed.ULisboa), Faculdade de Farmácia da Universidade de Lisboa, Avenida Professor Gama Pinto, 1649003, Lisboa, Portugal.

** Corresponding author. Research Institute for Medicines (iMed.ULisboa), Faculdade de Farmácia da Universidade de Lisboa, Avenida Professor Gama Pinto, 1649003, Lisboa, Portugal.

E-mail addresses: ibartolo@ff.ulisboa.pt (I. Bártolo), ntaveira@ff.ulisboa.pt (N. Taveira).
} 
Tenofovir alafenamide (TAF) is a novel prodrug of tenofovir. Compared with TDF, TAF is more stable in blood and plasma (Lee et al., 2005), has more favorable renal and bone safety profiles (Sax et al., 2014, 2015) and has higher anti-HIV-1 activity at ten times lower oral doses in humans as measured by the reduction in viral load (Ruane et al., 2013).

HIV exploits two distinct resistance mechanisms against NRTIs (reviewed in Iyidogan and Anderson, 2014). First, selection of resistance mutations such as $\mathrm{K} 65 \mathrm{R}$ in RT leads to an increase in discrimination against NRTIs by reducing the enzyme's binding affinity to the nucleoside analogue triphosphate derivatives or decreasing the incorporation rates of these nucleotides. In the excision repair mechanism, acquisition of thymidine analogue resistance mutations (TAMs) (i.e. M41L, D67N, K70R, L210W, T215F/Y and K219E/Q) leads to the phosphorolytic removal of the chain-terminating NRTI from the primer terminus subsequent to its incorporation into viral DNA. The excision repair mechanism is rarely used by HIV-2 to acquire resistance to NRTIs (Ntemgwa et al., 2009), which is related to the presence of a methionine at position 73 in RT, instead of lysine as found in HIV-1 (Alvarez et al., 2018).

In vitro studies have shown that HIV-1 has a higher genetic barrier to resistance to TAF than to TDF (Margot et al., 2016b). Nonetheless, like in TDF-based regimens, resistance to TAF-based regimens in HIV-1 infected patients is associated with the K65R substitution in RT (with or without S68G and A62V) and preexisting TAMs (M41L, D67N, K70R, L210W, T215Y/F, and K219Q/E/N/R) (Margot et al., 2006, 2016a, 2017; McColl et al., 2004; Miller et al., 2004).

Very limited information exists regarding the activity of TDF and TAF on HIV-2. One study found that TDF inhibited the replication of HIV-2 strains ROD and EHO at similar $\mathrm{EC}_{50}$ values relative to HIV-1 strain IIIB $\quad\left(\mathrm{EC}_{50}=1.12 \mu \mathrm{g} / \mathrm{ml}\right.$ and $1.05 \mu \mathrm{g} / \mathrm{ml}$ vs $\left.1.15 \mu \mathrm{g} / \mathrm{ml}\right)$ (Witvrouw et al., 2004). Similar results were found in another study comparing the sensitivity of $\mathrm{HIV}-2_{\mathrm{ROD}}$ and $\mathrm{HIV}-1_{\mathrm{NL} 4-3}$ to TDF $\left(\mathrm{EC}_{50}=7.2 \mu \mathrm{M}\right.$ vs $7.2 \mu \mathrm{M}$ ) (Smith et al., 2008). One recent in vitro study performed on a few primary isolates $(\mathrm{n}=3)$ has shown that TAF inhibits HIV-2 replication with a mean $\mathrm{EC}_{50}$ of $1.83 \mathrm{nM}$ (compared with $3.63 \mathrm{nM}$ for HIV-1) (Callebaut et al., 2015). In HIV-2 infected patients resistance to TDF occurs via selection of the K65R and Q151M mutations (Damond et al., 2004). V111I may be coselected with Q151M in some HIV-2 patients and increases the replication capacity of viruses with K65R and Q151M (Charpentier et al., 2013; Damond et al., 2005; Descamps et al., 2004; Deuzing et al., 2015).

OBP-601 (2,3-didehydro-3-deoxy-4-ethynylthymidine) is a novel thymidine analogue that inhibits reverse transcriptase activity. Relative to stavudine, OBP-601 is more potent against HIV-1 and causes less cellular and mitochondrial toxicity in cell culture (Dutschman et al., 2004). It is also active against most NRTI-resistant HIV-1 mutants (Li et al., 2013; Nitanda et al., 2005). In a phase IIb clinical trial the combination of lamivudine (3TC), efavirenz (EFV), and OBP601 (400 $\mathrm{mg}$ once a day) resulted in virologic suppression in 94\% of HIV-1infected subjects after 24 weeks of treatment, compared with $89 \%$ in the combination TDF (300 mg once a day) + 3TC + EFV. However, this trial was terminated due to higher rates of resistance (11\% OBP-601 vs $1 \%$ for TDF) and gains in both peripheral and central fat for patients taking OBP-601 (Gupta et al., 2016). Interestingly, a recent study performed mainly with lab-adapted HIV-2 isolates (6 of 8) from ARV-naïve patients found that OBP-601 was 9.5-fold more potent against HIV-2 than against HIV-1 in vitro (mean $\mathrm{EC}_{50}$ for HIV-1 was $610.00 \mathrm{nM}$ vs $64.12 \mathrm{nM}$ for HIV-2) suggesting that OBP-601 at lower doses may be useful to treat HIV-2 infected patients (Smith et al., 2015). Using site directed mutagenesis the authors also found that K65R mutation conferred HIV-2 $2_{\text {ROD }}$ 3.2-fold hypersusceptibility to OBP-601 whereas Q151M alone had no effect in susceptibility. On the other hand, M184V and $\mathrm{K} 65 \mathrm{R}+\mathrm{M} 184 \mathrm{~V}$ HIV-2 ${ }_{\mathrm{ROD}}$ mutants were 15- and 16-fold more resistant to OBP-601, respectively; even higher levels of resistance were observed for Q151M + M184V, K65R + Q151M + M184V and
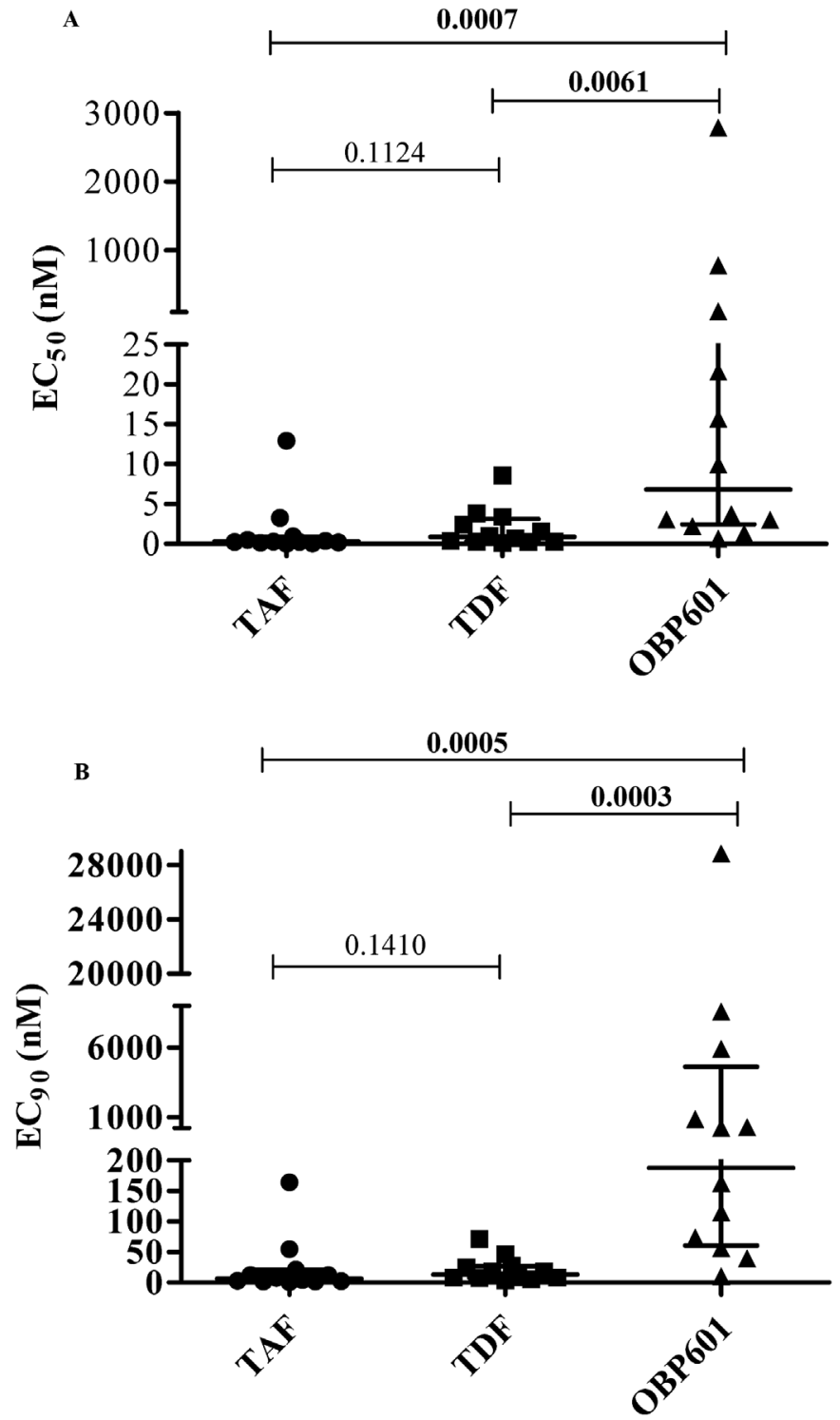

Fig. 1. Activity of TAF, TDF and OBP-601 against primary isolates of HIV-2. Comparison of $\mathrm{EC}_{50}$ (A) and $\mathrm{EC}_{90}$ (B) values of TAF, TDF and OBP-601 against 12 HIV-2 primary isolates. IC50 and IC90 best-fit values for each isolate were inferred from sigmoidal dose-response (variable slope) curves and represent geometric mean values. Bars represent mean values and 95\% confidence interval. $\mathrm{P}$ values were obtained comparing best-fit values using the Mann Whitney test.

$\mathrm{K} 65 \mathrm{R}+\mathrm{N} 69 \mathrm{~S}+\mathrm{V} 111 \mathrm{I}+\mathrm{Q} 151 \mathrm{M}+\mathrm{M} 184 \mathrm{~V}$ mutants (53-, 111- and 105-fold, respectively).

In this study we performed the first comparative evaluation of the activity of TDF, TAF and OBP-601 against primary isolates of HIV-2 obtained from drug naïve patients and patients failing ART.

TAF and TDF were provided by Gilead Sciences. OBP-601 was provided by Oncolys BioPharma. All but three of the twelve HIV-2 group A isolates used in this study were described before (Borrego et al., 2012; Doring et al., 2016). Three were obtained from drug naïve patients and nine were from drug-experienced patients (Table S1). The three new isolates, named 10PTHSJIG, 15PTHSJIG and 15PTHCEC, were obtained recently from two patients failing therapy. HIV-1 reference strain NL4-3 was obtained by transfection of HEK293T cells with pNL4-3 plasmid using Fugene 6 reagent (Roche, Switzerland) according to manufacturer's instructions.

The antiviral activity of TAF, OBP-601 and TDF was evaluated using 
Table 1

Activity of TDF, TAF and OBP-601 against each HIV-2 isolate as measured by the EC50.

\begin{tabular}{|c|c|c|c|c|}
\hline \multirow[t]{2}{*}{ Isolates } & \multicolumn{3}{|c|}{ Median $\mathrm{EC}_{50}(\mathrm{nM})\left(\right.$ fold change) ${ }^{\mathrm{a}}$} & \multirow[t]{2}{*}{ NRTI resistance mutations } \\
\hline & TDF & TAF & OBP-601 & \\
\hline HIV-1 NL4.3 & 1.19 & 0.48 & 16.56 & \\
\hline 00РТНСС20 & $3.81(2.23 / 3.2)$ & $0.40(1.18 / 0.83)$ & $780.25(49.48 / 47.11)$ & Q151M, K223R \\
\hline 00PTHDECT & $0.24(0.14 / 0.20)$ & $0.19(0.56 / 0.39)$ & $1.27(0.08 / 0.08)$ & \\
\hline 03РТнСС19 & $2.40(1.41 / 2.02)$ & $0.28(0.82 / 0.58)$ & $9.95(0.63 / 0.60)$ & \\
\hline 03РТHCC1 & $0.31(0.18 / 0.26)$ & $0.04(0.12 / 0.08)$ & $0.65(0.04 / 0.04)$ & \\
\hline 03РТНСС6 & $0.11(0.06 / 0.09)$ & $0.18(0.53 / 0.37)$ & $3.72(0.24 / 0.23)$ & \\
\hline 03РTHSM9 & $3.38(1.98 / 2.84)$ & $12.95(38.09 / 26.98)$ & $2781.21(176.36 / 167.95)$ & \\
\hline 04PTHSM10 & $1.57(0.92 / 1.32)$ & $0.54(1.59 / 1.12)$ & $2.99(0.19 / 0.18)$ & \\
\hline 10PTHSMAUC & $1.02(0.60 / 0.85)$ & $0.97(2.85 / 2.00)$ & $21.58(1.37 / 1.30)$ & \\
\hline 10PTHSMNC & $0.37(0.22 / 0.31)$ & $0.23(0.68 / 0.47)$ & $2.25(0.14 / 0.14)$ & \\
\hline 10PTHSJIG & $0.72(0.42 / 0.60)$ & $0.09(0.26 / 0.19)$ & $110.78(7.50 / 6.69)$ & V111I, Y115F, Q151M, M184V \\
\hline 15PTHSJIG & $0.28(0.40 / 0.24)$ & $0.27(0.79 / 0.55)$ & $15.71(0.99 / 0.95)$ & M184V \\
\hline 15РTHCEC & $8.57(5.01 / 7.20)$ & $3.27(9.61 / 6.81)$ & $3.03(0.19 / 0.18)$ & K65R, N69S \\
\hline Median EC50 (range) ${ }^{\mathrm{b}}$ & $0.87(0.11-8.57)$ & $0.27(0.04-12.95)$ & $6.83(0.65-2781.00)$ & \\
\hline
\end{tabular}

a Fold-change relative to HIV-2 drug-naive isolates/relative to HIV-1 ${ }_{\mathrm{NL} 4.3} ; 5-15$ fold - moderate level of resistance; $>15$ fold - high level of resistance. Fold-change values above 5 are indicated in bold letters.

$\mathrm{b}$ TDF vs TAF, $\mathrm{P}=0.1124$; TDF vs OBP-601, $\mathrm{P}=0.0061$; TAF vs OBP-601, $\mathrm{P}=0.0007$. P values were calculated using the Mann Whitney test.

a luciferase reporter gene assay in TZM-bl cells, as previously described (Borrego et al., 2012). At least two independent experiments were performed for each analysis and each assay was set up in triplicate wells. $\mathrm{EC}_{50}$ and $\mathrm{EC}_{90}$ were estimated by the sigmoidal dose-response (variable slope) equation in Prism version 5.01 for windows (GraphPad Software, USA). The Man-Whitney $U$ test was used to compare $\mathrm{EC}_{50}$ and $\mathrm{EC}_{90}$ values.

Drug resistance mutations in the RT-coding region of the pol gene were determined by sequencing analysis. Briefly, RNA was extracted from the isolates presenting phenotypic drug resistance using Nuclisens Isolation Kit (Organon Teknika, Holland) and nested PCR was done to obtain a $1305 \mathrm{bp}$ fragment corresponding to protease and the first half of the reverse transcriptase using outer primers JA218 and JA221 and inner primers JA219 and JA220 (Table S2). Thermal cycling conditions for amplification and sequencing of this region, primer numbers and positions have been described previously (Brandin et al., 2003). DNA sequences were obtained with Big Dye Terminator Cycle Sequencing Ready Reaction Kit (Applied Biosystems, USA) according to the manufacturers recommendations and the sequences were run on an automated DNA sequencer model 310 ABI Genetic Analyser (Applied Biosystems, USA). The GRADE algorithm was used to identify resistance mutations (http://www.hiv-grade.de/) and estimate virus susceptibility to the different antiretroviral drugs.

Evolutionary relationships and genotype of the viruses was determined by phylogenetic analysis of the RT sequences using the PhyML program implemented in SeaView software using the nearest-neighbor interchange heuristic search strategy and 1000 bootstrap replications.

In phylogenetic analysis all isolates clustered within group A which is the most common HIV-2 group in Portugal and worldwide (Visseaux et al., 2016) (Fig. S1). In addition, isolates 10PTHJSIG and 15PTHJSIG formed a monophyletic cluster confirming their common origin.

Maximum percentage of inhibition (MPI) of the HIV-2 isolates was similar for TAF, TDF and OBP-601 (TDF, 93.8\%; TAF, 94.1\%; OBP-601, $96.2 \%, \mathrm{P}>0.05$ ). Median $\mathrm{EC}_{50}$ of TAF against HIV-2 isolates was $0.27 \mathrm{nM}$ (range 0.04-12.95 nM) which was 3.2-fold lower compared to TDF (Fig. 1 and Table 1). In contrast, median $\mathrm{EC}_{50}$ of OBP-601 was significantly higher $(6.83 \mathrm{nM}$, range $0.65-2781 \mathrm{nM})$ than TDF and TAF (Fig. 1 and Table 1). Similar results were obtained for the $\mathrm{EC}_{90}$ indicating that OBP-601 is significantly less potent against HIV-2 than TAF and TDF [Median (range), TDF $13.49 \mathrm{nM}$ (3.95-71.43); TAF, $5.96 \mathrm{nM}$ (1.00-164.40); OBP-601, 188.20 (10.31-28843.00), $\mathrm{P}<0.001$ ]. Regarding TDF and OBP-601, our results are in line with those obtained by Smith and collaborators (Smith et al., 2015) with the lab-adapted isolate HIV-2 ROD9.
Two isolates showed moderate-level resistance (MLR) to OBP-601 (10PTHSJIG) or to TAF and TDF (15PTHCEC). Two other isolates showed high-level resistance (HLR) to OBP-601 (00PTHCC20) or to TAF and OBP-601 (03PTHSM9). Despite the HLR to TAF and OBP-601, no known NRTI resistance mutations were found in the RT of isolate 03PTHSM9, only some polymorphisms that so far have not been related with resistance (K4R, I5V, R22K, T58S, K64R, D86E, L109I, Y162H, I167V P176Q, G211N, Q228R, I244V). In contrast, Q151M and K223R substitutions were found in isolate 00PTHCC20 and V111I, Y115F, Q151M and M184V in 10PTHSJIG (Table 1). The latter was the only resistance mutation that remained in the isolate obtained from this patients five years later (15PTHSJIG) (Table 1). Finally, substitutions K65R and N69S were found in isolate 15PTHCEC.

In this study, we performed the first side-by-side characterization of the activity of the novel NRTIS TAF and OBP-601 against twelve primary isolates of HIV-2, nine of which were obtained from ART-experienced patients. So far only one study had examined the activity of TAF against primary isolates $(n=3)$ of HIV-2 (Callebaut et al., 2015); our results with 4-times more isolates and a different inhibition method were similar to this study $\left(\mathrm{EC}_{50}\right.$ of $1.6 \mathrm{nM}$ vs $1.8 \mathrm{nM}$ ) confirming that TAF is a potent inhibitor of HIV-2.

Two isolates obtained from two drug-experienced patients were resistant to TAF. Isolate 03PTHSM9 was highly resistance to TAF and to OBP-601 despite being sensitive to TDF. This occurred in the absence of canonical NRTI resistance mutations revealing that there are TAF and OBP-601-specific HIV-2 resistance mutations yet to be identified. Isolate 15PTHCEC was obtained in 2015 from a patient that initiated antiretroviral therapy in 2010 with ATZ/r + FTC/TDF. After several changes and interruptions of the therapeutic regimen, in July 2015, this patient started therapy with DTG + FTC/TDF, with viral load of 1677 RNA copies/ml and $\mathrm{CD}^{+}{ }^{+} \mathrm{T}$ cell counts of 436 cell/ul. Our results showing that the isolate obtained at this time was moderately resistant to TDF and TAF, and the presence of mutations K65R and N69S in the RT, are highly consistent with the history of failing therapy with multiple NRTIs including TDF.

OBP-601 had a potent activity against nine of the twelve (75\%) isolates that were tested confirming its potential usefulness against HIV2 (Smith et al., 2015). Two isolates from drug-experienced patients, 00PTHCC20 and 03PTHSM9, showed HLR to OBP-601. Isolate 03PTHSM9 had no known NRTI resistance mutations and was discussed above. Isolate 00PTHCC20 had the Q151M and K223R mutations that have been previously associated to HLR to AZT, d4T, ddI and ABC, and LLR to 3TC, FTC and TDF (Charpentier et al., 2013). Isolate 10PTHSJIG showed MLR to OBP-601 consistent with the resistance mutations 
present in the RT. Five years later this patient harboured an isolate (15PTHSJIG) that was fully sensitive to all tested drugs and that displayed only the M184V substitution that confers HLR to 3TC and FTC. This patient was on AZT/3TC + DRV/r + RAL from 2007 to 2009 with viral load decreasing from 127,968 RNA copies/ml to 789 copies/ml. From 2010 to 2013 a regimen with TDF + DRV/r + MVC150 was used changing to MVC + RAL + SQV/r in October 2013 and until April 2014 when therapy was interrupted. Therapy resumed in August 2015 with DRV/r + MVC150 + DTG. Hence, the long period of absence of NRTI pressure in this patient has allowed the return of the wild-type strain in 2015 which was sensitive to TAF, TDF and OPB-601 (Deeks et al., 2001; Paquet et al., 2011).

In conclusion, TAF has a potent activity against most multi-drug resistant HIV-2 isolates and should be considered for the treatment of HIV-2 infected individuals failing therapy. Identification of one isolate with resistance to TAF and OBP-601 without canonical resistance mutations is of concern and warrants further investigation to identify the determinants of resistance.

\section{Acknowledgments}

Financial support for this research was provided by the Fundação para a Ciência e a Tecnologia (FCT), Portugal (project VIH/SAU/0029/ 2011) and by the LIFE project of the European and Developing Countries Clinical Trials Partnership (EDCTP) program supported by the European Union. Inês Bártolo is supported by a post-doc fellowship (SFRH/BPD/76225/2011) from Fundação para a Ciência e a Tecnologia (FCT).

\section{Appendix A. Supplementary data}

Supplementary data related to this article can be found at https:// doi.org/10.1016/j.antiviral.2018.10.018.

\section{References}

Alvarez, M., Nevot, M., Mendieta, J., Martinez, M.A., Menendez-Arias, L., 2018. Amino acid residues in HIV-2 reverse transcriptase that restrict the development of nucleoside analogue resistance through the excision pathway. J. Biol. Chem. 293, 2247-2259.

Borrego, P., Calado, R., Marcelino, J.M., Bartolo, I., Rocha, C., Cavaco-Silva, P., Doroana, M., Antunes, F., Maltez, F., Caixas, U., Barroso, H., Taveira, N., 2012. Baseline susceptibility of primary HIV-2 to entry inhibitors. Antivir. Ther. 17, 565-570.

Brandin, E., Lindborg, L., Gyllensten, K., Brostrom, C., Hagberg, L., Gisslen, M., Tuvesson, B., Blaxhult, A., Albert, J., 2003. Pol gene sequence variation in Swedish HIV-2 patients failing antiretroviral therapy. AIDS Res. Hum. Retrovir. 19, 543-550.

Callebaut, C., Stepan, G., Tian, Y., Miller, M.D., 2015. In vitro virology profile of tenofovir alafenamide, a novel oral prodrug of tenofovir with improved antiviral activity compared to that of tenofovir disoproxil fumarate. Antimicrob. Agents Chemother. 59, 5909-5916.

Carvalho, A.C., Valadas, E., Franca, L., Carvalho, C., Aleixo, M.J., Mendez, J., Marques, R., Sarmento, A., Doroana, M., Antunes, F., Branco, T., Aguas, M., Sarmento, E.C.R., Lazarus, J.V., Barros, H., 2012. Population mobility and the changing epidemics of HIV-2 in Portugal. HIV Med. 13, 219-225.

Cazein, F., Pillonel, J., Le Strat, Y., Pinget, R., Le Vu, S., Brunet, S., Thierry, D., Brand, D., Leclerc, M., Benyelles, L., Da Costa, C., Barin, F., Lot, F., 2015. New HIV and AIDS diagnoses, France, 2003-2013. Bull Epidemiol Hebd. 9-10, 152-161.

Charpentier, C., Camacho, R., Ruelle, J., Kaiser, R., Eberle, J., Gurtler, L., Pironti, A., Sturmer, M., Brun-Vezinet, F., Descamps, D., Obermeier, M., 2013. HIV-2EU: supporting standardized HIV-2 drug resistance interpretation in Europe. Clin. Infect. Dis. $56,1654-1658$

Damond, F., Benard, A., Balotta, C., Boni, J., Cotten, M., Duque, V., Ferns, B., Garson, J., Gomes, P., Goncalves, F., Gottlieb, G., Kupfer, B., Ruelle, J., Rodes, B., Soriano, V., Wainberg, M., Taieb, A., Matheron, S., Chene, G., Brun-Vezinet, F., 2011. An international collaboration to standardize HIV-2 viral load assays: results from the 2009 ACHI(E)V(2E) quality control study. J. Clin. Microbiol. 49, 3491-3497.

Damond, F., Collin, G., Matheron, S., Peytavin, G., Campa, P., Delarue, S., Taieb, A., Benard, A., Chene, G., Brun-Vezinet, F., Descamps, D., 2005. Letter. In vitro phenotypic susceptibility to nucleoside reverse transcriptase inhibitors of HIV-2 isolates with the Q151M mutation in the reverse transcriptase gene. Antivir. Ther. 10, 861-865.

Damond, F., Matheron, S., Peytavin, G., Campa, P., Taieb, A., Collin, G., Delaunay, C., Chene, G., Brun-Vezinet, F., Descamps, D., 2004. Selection of K65R mutation in HIV2 -infected patients receiving tenofovir-containing regimen. Antivir. Ther. 9 , 635-636. de Silva, T.I., Cotten, M., Rowland-Jones, S.L., 2008. HIV-2: the forgotten AIDS virus. Trends Microbiol. 16, 588-595.

Deeks, S.G., Wrin, T., Liegler, T., Hoh, R., Hayden, M., Barbour, J.D., Hellmann, N.S., Petropoulos, C.J., McCune, J.M., Hellerstein, M.K., Grant, R.M., 2001. Virologic and immunologic consequences of discontinuing combination antiretroviral-drug therapy in HIV-infected patients with detectable viremia. N. Engl. J. Med. 344, 472-480.

Descamps, D., Damond, F., Matheron, S., Collin, G., Campa, P., Delarue, S., Pueyo, S., Chene, G., Brun-Vezinet, F., 2004. High frequency of selection of K65R and Q151M mutations in HIV-2 infected patients receiving nucleoside reverse transcriptase inhibitors containing regimen. J. Med. Virol. 74, 197-201.

Deuzing, I.P., Charpentier, C., Wright, D.W., Matheron, S., Paton, J., Frentz, D., van de Vijver, D.A., Coveney, P.V., Descamps, D., Boucher, C.A., Beerens, N., 2015. Mutation V111I in HIV-2 reverse transcriptase increases the fitness of the nucleoside analogueresistant K65R and Q151M viruses. J. Virol. 89, 833-843.

Doring, M., Borrego, P., Buch, J., Martins, A., Friedrich, G., Camacho, R.J., Eberle, J., Kaiser, R., Lengauer, T., Taveira, N., Pfeifer, N., 2016. A genotypic method for determining HIV-2 coreceptor usage enables epidemiological studies and clinical decision support. Retrovirology 13, 85.

Dutschman, G.E., Grill, S.P., Gullen, E.A., Haraguchi, K., Takeda, S., Tanaka, H., Baba, M., Cheng, Y.C., 2004. Novel 4'-substituted stavudine analog with improved anti-human immunodeficiency virus activity and decreased cytotoxicity. Antimicrob. Agents Chemother. 48, 1640-1646.

Gottlieb, G.S., Eholie, S.P., Nkengasong, J.N., Jallow, S., Rowland-Jones, S., Whittle, H.C., Sow, P.S., 2008. A call for randomized controlled trials of antiretroviral therapy for HIV-2 infection in West Africa. AIDS 22, 2069-2072 discussion 2073-2064.

Gottlieb, G.S., Sow, P.S., Hawes, S.E., Ndoye, I., Redman, M., Coll-Seck, A.M., Faye-Niang, M.A., Diop, A., Kuypers, J.M., Critchlow, C.W., Respess, R., Mullins, J.I., Kiviat, N.B., 2002. Equal plasma viral loads predict a similar rate of CD4 $+\mathrm{T}$ cell decline in human immunodeficiency virus (HIV) type 1- and HIV-2-infected individuals from Senegal, West Africa. J. Infect. Dis. 185, 905-914.

Gupta, S.K., McComsey, G.A., Lombaard, J., Echevarria, J., Orrell, C., Avihingsanon, A., Osiyemi, O., Santoscoy, M., Ray, N., Stock, D.A., Joshi, S.R., Hanna, G.J., Lataillade, M., 2016. Efficacy, safety, bone and metabolic effects of HIV nucleoside reverse transcriptase inhibitor BMS-986001 (AI467003): a phase 2b randomised, controlled, partly blinded trial. Lancet HIV 3, e13-e22.

Gurjar, R.S., Ravi, V., Desai, A., 2009. Molecular epidemiology of HIV type 2 infections in South India. AIDS Res. Hum. Retrovir. 25, 363-372.

Hansmann, A., Schim van der Loeff, M.F., Kaye, S., Awasana, A.A., Sarge-Njie, R, O'Donovan, D., Ariyoshi, K., Alabi, A., Milligan, P., Whittle, H.C., 2005. Baseline plasma viral load and CD4 cell percentage predict survival in HIV-1- and HIV-2-infected women in a community-based cohort in the Gambia. J. Acquir. Immune Defic. Syndr. 38, 335-341.

Iyidogan, P., Anderson, K.S., 2014. Recent findings on the mechanisms involved in tenofovir resistance. Antivir. Chem. Chemother. 23, 217-222.

Lee, W.A., He, G.X., Eisenberg, E., Cihlar, T., Swaminathan, S., Mulato, A., Cundy, K.C., 2005. Selective intracellular activation of a novel prodrug of the human immunodeficiency virus reverse transcriptase inhibitor tenofovir leads to preferential distribution and accumulation in lymphatic tissue. Antimicrob. Agents Chemother. 49, 1898-1906.

Li, Z., Terry, B., Olds, W., Protack, T., Deminie, C., Minassian, B., Nowicka-Sans, B., Sun, Y., Dicker, I., Hwang, C., Lataillade, M., Hanna, G.J., Krystal, M., 2013. In vitro crossresistance profile of nucleoside reverse transcriptase inhibitor (NRTI) BMS-986001 against known NRTI resistance mutations. Antimicrob. Agents Chemother. 57, 5500-5508.

Margot, N., Cox, S., Das, M., McCallister, S., Miller, M.D., Callebaut, C., 2017. Infrequent development of drug resistance in HIV-1-infected treatment-naive subjects after 96 weeks of treatment with elvitegravir/cobicistat/emtricitabine/tenofovir alafenamide or elvitegravir/cobicistat/emtricitabine/tenofovir disoproxil fumarate. Antivir. Ther. 22, 443-446.

Margot, N.A., Kitrinos, K.M., Fordyce, M., McCallister, S., Miller, M.D., Callebaut, C., 2016a. Rare emergence of drug resistance in HIV-1 treatment-naive patients after 48 weeks of treatment with elvitegravir/cobicistat/emtricitabine/tenofovir alafenamide. HIV Clin. Trials 17, 78-87.

Margot, N.A., Liu, Y., Miller, M.D., Callebaut, C., 2016b. High resistance barrier to tenofovir alafenamide is driven by higher loading of tenofovir diphosphate into target cells compared to tenofovir disoproxil fumarate. Antivir. Res. 132, 50-58.

Margot, N.A., Lu, B., Cheng, A., Miller, M.D., 2006. Resistance development over 144 weeks in treatment-naive patients receiving tenofovir disoproxil fumarate or stavudine with lamivudine and efavirenz in study 903. HIV Med. 7, 442-450.

McColl, D.J., Margot, N.A., Wulfsohn, M., Coakley, D.F., Cheng, A.K., Miller, M.D., 2004. Patterns of resistance emerging in HIV-1 from antiretroviral-experienced patients undergoing intensification therapy with tenofovir disoproxil fumarate. J. Acquir. Immune Defic. Syndr. 37, 1340-1350.

Menendez-Arias, L., Alvarez, M., 2014. Antiretroviral therapy and drug resistance in human immunodeficiency virus type 2 infection. Antivir. Res. 102, 70-86.

Miller, M.D., Margot, N., Lu, B., Zhong, L., Chen, S.S., Cheng, A., Wulfsohn, M., 2004 Genotypic and phenotypic predictors of the magnitude of response to tenofovir disoproxil fumarate treatment in antiretroviral-experienced patients. J. Infect. Dis. 189, 837-846.

Nitanda, T., Wang, X., Kumamoto, H., Haraguchi, K., Tanaka, H., Cheng, Y.C., Baba, M., 2005. Anti-human immunodeficiency virus type 1 activity and resistance profile of 2',3'-didehydro-3'-deoxy-4'-ethynylthymidine in vitro. Antimicrob. Agents Chemother. 49, 3355-3360.

Ntemgwa, M., Brenner, B.G., Oliveira, M., Moisi, D., Wainberg, M.A., 2007. Natural polymorphisms in the human immunodeficiency virus type 2 protease can accelerate time to development of resistance to protease inhibitors. Antimicrob. Agents 
Chemother. 51, 604-610.

Ntemgwa, M.L., d'Aquin Toni, T., Brenner, B.G., Camacho, R.J., Wainberg, M.A., 2009. Antiretroviral drug resistance in human immunodeficiency virus type 2. Antimicrob. Agents Chemother. 53, 3611-3619.

Paquet, A.C., Baxter, J., Weidler, J., Lie, Y., Lawrence, J., Kim, R., Bates, M., Coakley, E., Chappey, C., 2011. Differences in reversion of resistance mutations to wild-type under structured treatment interruption and related increase in replication capacity. Plos One 6, e14638.

Ruane, P.J., DeJesus, E., Berger, D., Markowitz, M., Bredeek, U.F., Callebaut, C., Zhong, L., Ramanathan, S., Rhee, M.S., Fordyce, M.W., Yale, K., 2013. Antiviral activity, safety, and pharmacokinetics/pharmacodynamics of tenofovir alafenamide as 10-day monotherapy in HIV-1-positive adults. J. Acquir. Immune Defic. Syndr. 63, 449-455.

Sax, P.E., Wohl, D., Yin, M.T., Post, F., DeJesus, E., Saag, M., Pozniak, A., Thompson, M., Podzamczer, D., Molina, J.M., Oka, S., Koenig, E., Trottier, B., Andrade-Villanueva, J., Crofoot, G., Custodio, J.M., Plummer, A., Zhong, L., Cao, H., Martin, H., Callebaut, C., Cheng, A.K., Fordyce, M.W., McCallister, S., 2015. Tenofovir alafenamide versus tenofovir disoproxil fumarate, coformulated with elvitegravir, cobicistat, and emtricitabine, for initial treatment of HIV-1 infection: two randomised, double-blind, phase 3, non-inferiority trials. Lancet 385, 2606-2615.

Sax, P.E., Zolopa, A., Brar, I., Elion, R., Ortiz, R., Post, F., Wang, H., Callebaut, C., Martin,
H., Fordyce, M.W., McCallister, S., 2014. Tenofovir alafenamide vs. tenofovir disoproxil fumarate in single tablet regimens for initial HIV-1 therapy: a randomized phase 2 study. J. Acquir. Immune Defic. Syndr. 67, 52-58.

Smith, R.A., Gottlieb, G.S., Anderson, D.J., Pyrak, C.L., Preston, B.D., 2008. Human immunodeficiency virus types 1 and 2 exhibit comparable sensitivities to Zidovudine and other nucleoside analog inhibitors in vitro. Antimicrob. Agents Chemother. 52, 329-332.

Smith, R.A., Raugi, D.N., Wu, V.H., Leong, S.S., Parker, K.M., Oakes, M.K., Sow, P.S., Ba, S., Seydi, M., Gottlieb, G.S., 2015. The nucleoside analog BMS-986001 shows greater in vitro activity against HIV-2 than against HIV-1. Antimicrob. Agents Chemother. 59, 7437-7446.

Soares, R.S., Tendeiro, R., Foxall, R.B., Baptista, A.P., Cavaleiro, R., Gomes, P., Camacho, R., Valadas, E., Doroana, M., Lucas, M., Antunes, F., Victorino, R.M., Sousa, A.E. 2011. Cell-associated viral burden provides evidence of ongoing viral replication in aviremic HIV-2-infected patients. J. Virol. 85, 2429-2438.

Visseaux, B., Damond, F., Matheron, S., Descamps, D., Charpentier, C., 2016. Hiv-2 molecular epidemiology. Infect. Genet. Evol. 46, 233-240.

Witvrouw, M., Pannecouque, C., Switzer, W.M., Folks, T.M., De Clercq, E., Heneine, W., 2004. Susceptibility of HIV-2, SIV and SHIV to various anti-HIV-1 compounds: implications for treatment and postexposure prophylaxis. Antivir. Ther. 9, 57-65. 